
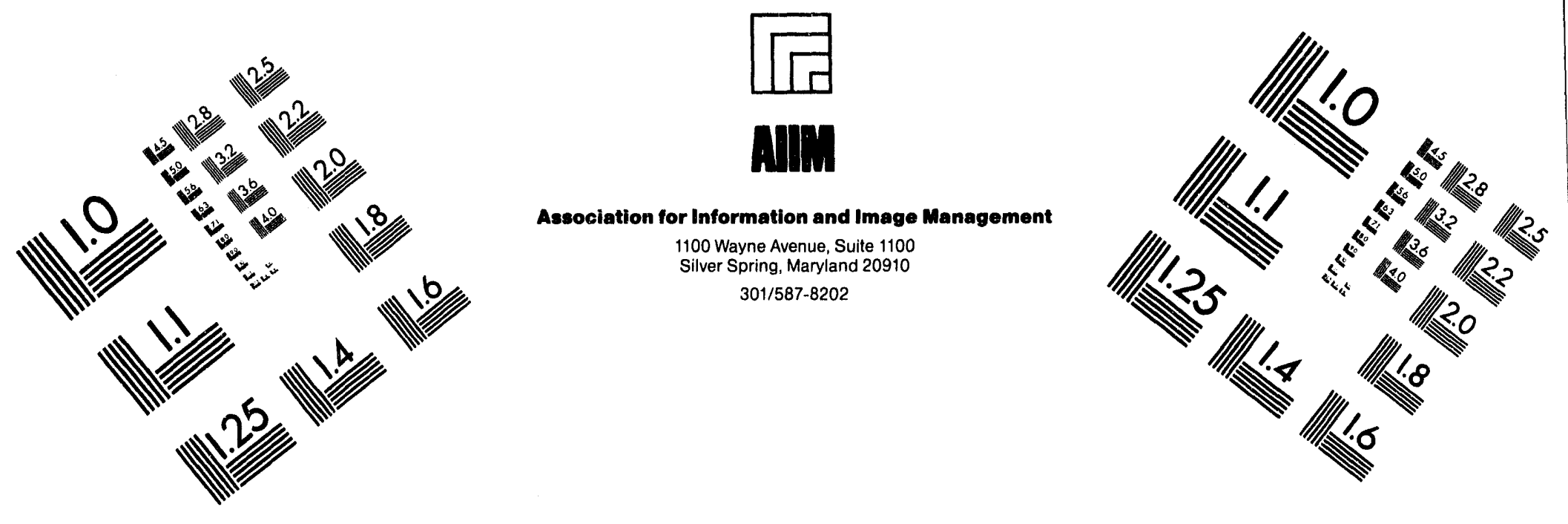

\title{
Centimeter
}

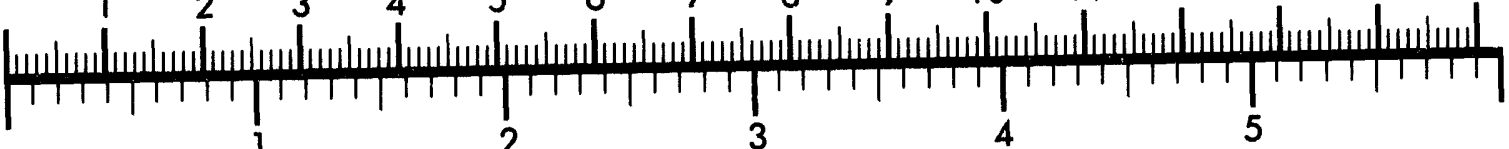
Inches
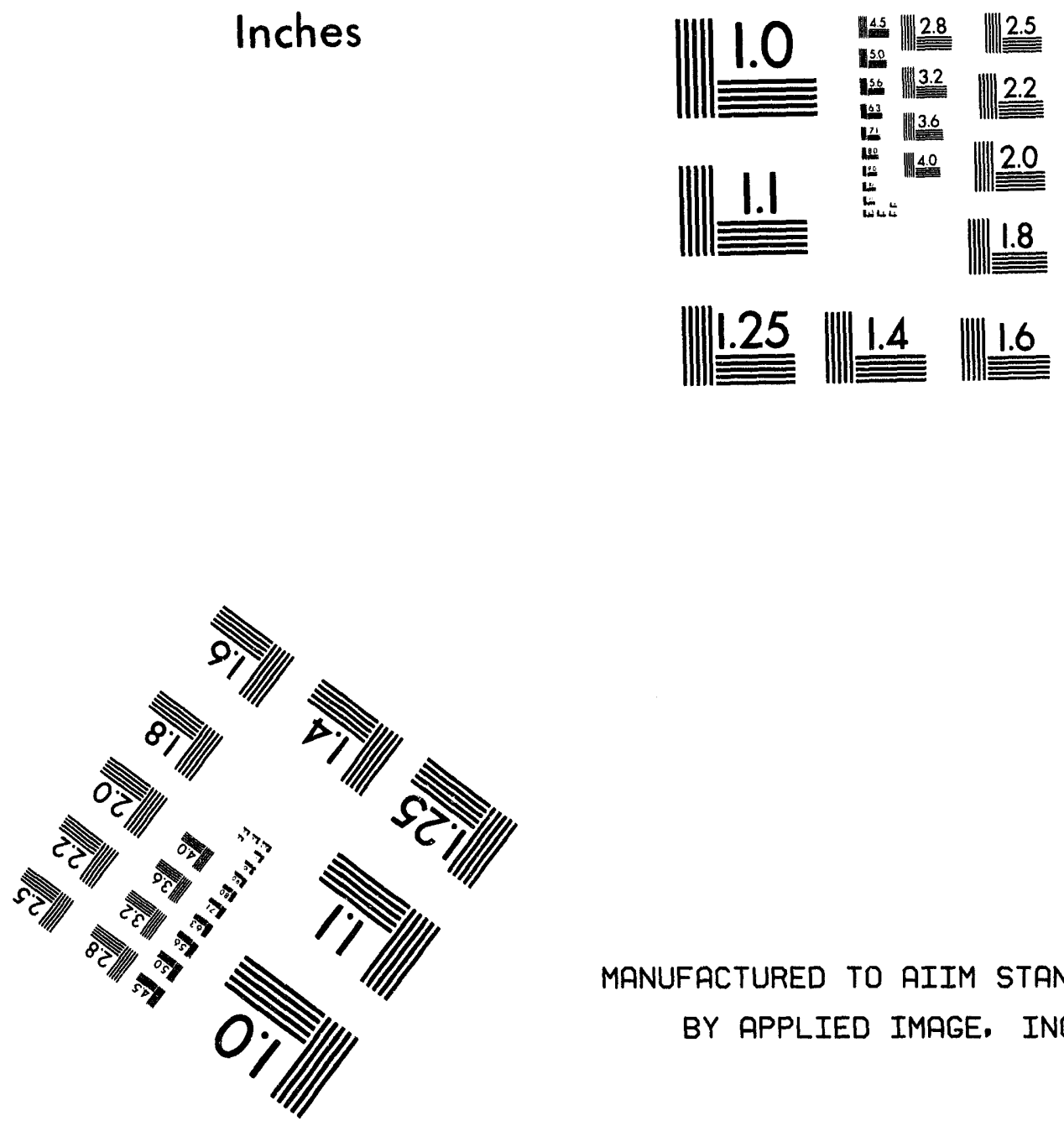

MANUFACTURED TO AIIM STANDARDS

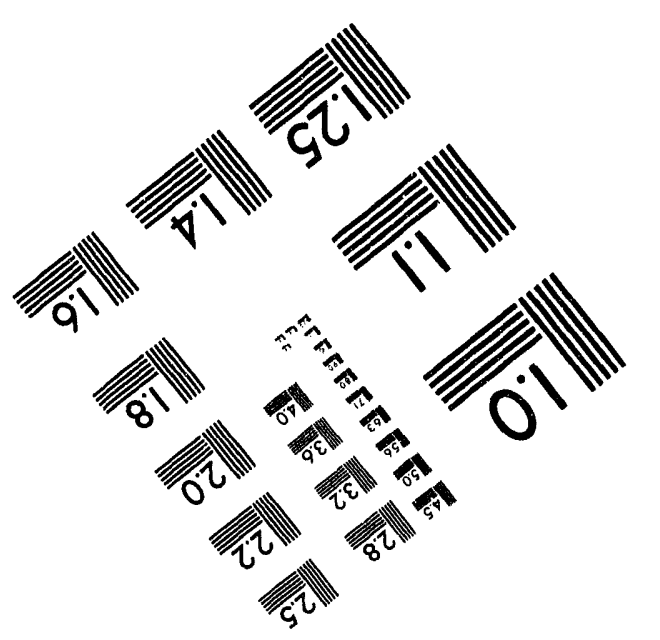



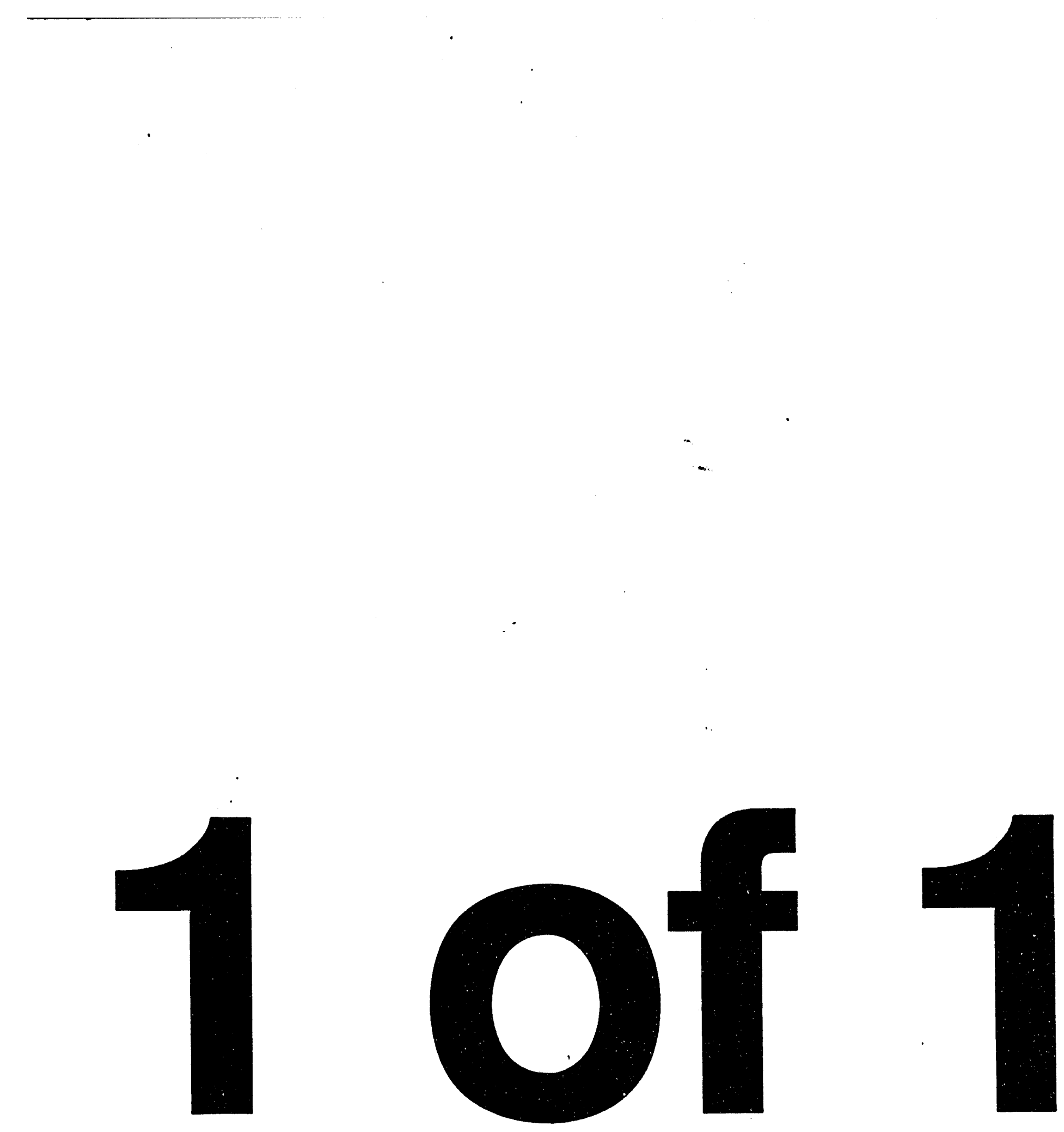


\title{
$\operatorname{Conf}-940440--3$ \\ PNL-SA-24049
}

\section{A KEVIEW OF FUNDAMENTAL COATING ISSUES FOR HIGH TEMPERATURE COMPOSITES}

\author{
E. L. Courtright
}

April 1994

Presented at the

International Conference on Metallurgical

Coatings and Thin Films

April 25-29, 1994

San Diego, California

Prepared for

the U.S. Department of Energy

under Contract DE-AC06-76RLO 1830

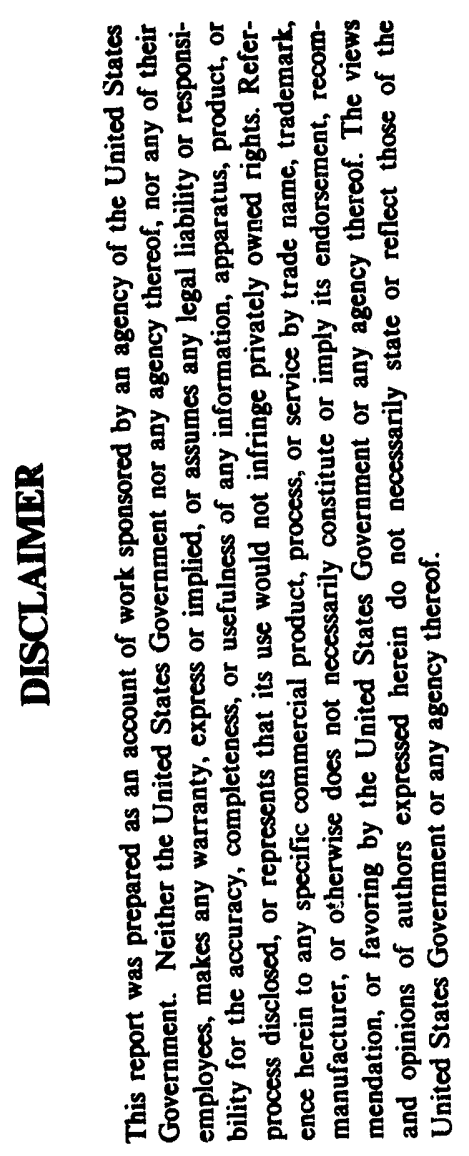

Pacific Northwest Laboratory

Richland, Washington 99352 
A Review of Fundamental Coating Issues for

High Temperature Composites

\author{
E. I. Courtright \\ Pacific Northiest Laboratory \\ Richland, WA*
}

\title{
Abstract
}

This review adoressels many of the fundamentai issues associaced with the use of coatings in high temperature, aggressive, environmerts with specific emphasis on multi-component composites. A major concern is damage caused by the permeation of oxygen into matrix cracks causing internal oxidation and attacking 3 along fiber/matrix interfaces. Many prospective coatings that might be used to protect composites are susceptible to hot corrosion, particularly by small vanadate concentrations which can degrade the coating and, thereby, enhance the permeation of other aggressive species. The mechanical stability of coating systems is also a major consideration in determining performance. Large differences in thermal expansion coefficients between coating and the composite substrate are not necessarily ameliorated by the practice of grading interfaces. However, the use of functionally graded coatings can be beneficial in reducing interlaminar shear and across-ply strains. Crack management, including the use of sealants, can be an essential part of a functional design, but the thermochemical stability of the glass sealant must be considered at elevated temperatures....

\#PNL is operated for the U.S. Department of Energy by the Battelle Memorial Institute under contract DE-AC06-76RLO 1830 . 
1. Introduction

The successful use of high performance composites with metal, intermetallic, or ceramic matrices will, in many cases, depend upon the

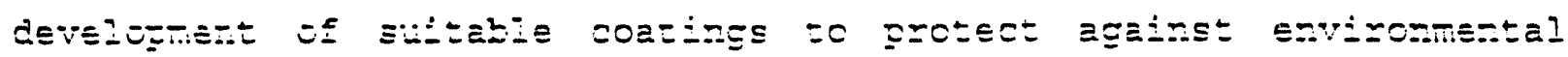
degradation. For example, promising titanium alloy and titanium intermetallic composites undergo damage when thermally fatigued in oxidizing atmospheres. (2,2) Many ceramic matrix composites, CMC's, lose a significant fraction of their room temperature tensile properties after pre-exposure in air at $1000^{\circ} \mathrm{C}^{(3)}$, and some non-oxide reinforced oxide matrix composites, that are thermochemically compatible in an inert environment; form intermediate compounds when exposed to oxygen. (4) SiC and $\mathrm{Si}_{3} \mathrm{~N}_{4}$ ceramics and composites generally display excellent oxidation resistance, but corrode severely in the presence of alkali compounds(5) and require coatings for use in industrial stack (gas environments. (6)

Protective coatings may provide solutions to these problems if the integrity of the coating can be maintained throughout the projected service life of the component. In some composites, the constitutive phases are not thermochemically stable in contact with one another, and fiber coatings are used to prevent interphase formation. However, the main purpose of fiber coatings is usually to reduce interfacial shear stresses and, thereby, improve toughness. (7,8) Exterior coatings are required to prevent generalized attack, to reduce localized attack on exposed fiber ends, and to prevent ingress of reactive gasses into matrix cracks or down incerīaces between macrix and fiber.

This paper reviews many of the pertinent issues associated with the application of coatings for high temperature materials with specific attention given to the luigue problems of composites. 
2. Damage Mechanisms

A schematic illustration of the principal damage mechanisms and partial processes that take place between a composite, its coating, and

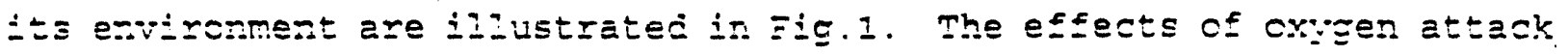
are highlighted and will be discussed in more detail, however other aggressive species, e.g. $\mathrm{Cl}_{2}, \mathrm{Na}_{2} \mathrm{SO}_{4}$, and $\mathrm{H}_{2}$, are also important.

In the case of oxygen permeation, an oxide scale may form at the composite/coating interface, ard this can be either beneficial or detrimental. If a dense compact scale-is formed, it may provide additional protection against ingress of oxygen; however, the molar volume expansion of the reactant products can induce stresses which damage the protective coating. In addition, volatile species, e.g. CO, $\mathrm{N}_{2}$, SiCl 4 , may evolve as, reaction by-products and these gases must diffuse outwardly to the surface. If their diffusion is restricted, gas bubbles will form and, under certain conditions, the internal pressures can rise to the point of disrupting the coating. If oxygen or other reactive species penetrate to the composite surface, selective attack may occur along matrix/fiber interfaces and damage the coatings which have been introduced to enhance interfacial sliding. . Localized attack may progress rapidly down these interfaces and cause deterioration in overall mechanical properties.. This can be a particular problem in brittle matrix composites where prior matrix cracking has occurred and in composite systems subjected to thermal or thermomechanical fatigue.


adherence between coating and substrate... Usually, the soating process is selected to provide acceptable adherence and great care is employed to minimize or eliminate surface contamination. coating systems must be chosen that will be thermochemically stable at operating temperature and differences in thermal expansion between coating and substrate must be kept to a mininum. It is not. always possible to balance these factors 
and compromises in CTE mismatch are often accepted. The result can be an unacceptably high stress level that eventually leads to spallation or cracking.

Actuaily, the Eormation of cracks, Eisholes, or othez coating defects are inevitable, i.e. there is no perfect coating system. Thus, crack management becomes a major consideration in the development of engineered coating system. Cracks may open and close with the application of loads or through exposure to thermal cycling. If the openings are sufficiently large at a reactive temperature, the ingress of molecular oxygen or other aggressive species will lead to internal damage. One approach is to utilize glass sealants or employ additives that have self-healing properties during high temperature exposure. Coatings which employ sealants can be effective; however, finding a sealant which is functional over a large temperature range is not an easy task.

In the sections that follow, the issues summarized above will be addressed in more detail.

\subsection{Oxygen Permeability}

The rapid inward diffusion of oxygen through a coating can attack the surface, jamage the reinforcement fiber, or attack the interface between matrix and reinforcement as illustrated in Figs. $1 \mathrm{a}$ and $1 \mathrm{~b}$. For high temperature service, a coating with low permeability to oxygen is highly desirable. The temperature dependent oxygen permeabilities for several ceramic oxides, that are potential candidate coating systems, are shown in Fig. 2. One-dimensional diffusion calculations have been used to provide a guideline for determining minimum permeability requirements, and a permeability of $10^{-10} \mathrm{gO}_{2} / \mathrm{cm}$ is suggested for a lower bound based on conservative assumptions for the allowable reaction thickness of the underlying component, e.g. fiber or composite, and a 1000 hour 
Iifetime. (9) Alumina, beryllia, and silica will all meet this requirement below $1500^{\circ} \mathrm{C}$. Silica has the lowest permeability to oxygen above $1300^{\circ} \mathrm{C}$, but alumina and beryllia appear to be lower below this temperature. This

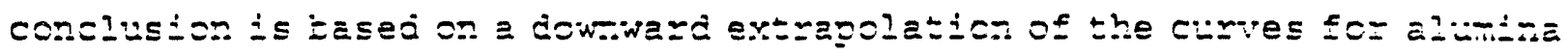
and beryllia in Fig. 2 along with corroborating diffusion data reported at lower temperatures that shows similar trends and activation energies. ${ }^{(20-12)}$

The impact of oxygen permeation can be visualized by considering what would happen if niobium is used as a ductile reinforcement for the toughening of molydisilicide in an oxidizing environment. Lu, Evans, Hecht, and Mehrabian ${ }^{(13)}$ indicate that a yttria $\left(\mathrm{Y}_{2} \mathrm{O}_{3}\right)$. coating is required to prevent the formation of intermediate silicide phases. At any point where there is exposure of the yttria coated miobium;-the-flux of oxygen; $\mathrm{JO}_{2}$, through the coating will be given by $\pi \mathrm{O}_{2} / \delta$ where $\pi \mathrm{O}_{2}$ is the oxygen permeability at 0.21 atmospheres of $\mathrm{O}_{2}$ which can be obtained from Fig. 2 and is on the order of $5 \times 10^{-10} \mathrm{gO}_{2} / \mathrm{cm}^{2} \mathrm{~s}$ at $1200^{\circ} \mathrm{C}$. - The thickness, $\delta$, of the yttria coating should be about $1 \mu \mathrm{m}$, and the consumption of the underlying niobium with reaction thickness, $n$, can be determined from:

$$
t=\frac{n \cdot \alpha}{2 v_{s} \cdot J_{O_{1}}}
$$

where $v_{s}$ is the molar volume of the substrate and $\alpha$ is the 2.5 moles of oxygen needed to react with niobium and produce one mole of $\mathrm{Nb}_{2} \mathrm{O}_{5}$. - If we set an allowable reaction thickness,.. $\Omega$, for the niobium at $1 \mu \mathrm{m}$,..we can estimate from equation (1) that $1 \mu \mathrm{m}$ of $\mathrm{Nb}$ will be consumed and converted to oxidation product in about six minutes at $1200^{\circ} \mathrm{C}$... This: of course, precludes the use of this composite system in oxidizing atmospheres at this temperature without the protection of some kind of coating. If that coating were to be $5 \mu \mathrm{m}$ of silica produced by the oxidation of the molydisilicide matrix, then this would become the rate limiting barrier. 
Assuming that there are no other reaction products between $\mathrm{SiO}_{2}$ and $\mathrm{Y}_{2} \mathrm{O}_{3}$ that are less resistant to the permeation of oxygen, then the time required to consume $1 \mu \mathrm{m}$ of niobium increases to -130 hours. This is beะter buะ certainly be required before internal damage progressed to the point where overall composite performance would be adversely affected.

If we choose the lower curve shown in Fig. 2 for silica permeability, then the time to reach the consumption limit for the calculation discussed above increases to about 600 hours. The wide variation for the oxygen permeability in silica, shown in Fig. 2 , is thought to be due to impurities. While the exact transport mechanism a matter of some debate, it is generally accepted that oxygen diffuses through amorphous silica as a diatomic molecule and the structure of the internal network is very sensitive to impurities. Molecular diffusion is supported by the lower activation energy compared to crystalline alumina where diffusion is controlled by charged defects. (14) However, Luthra ${ }^{(15)}$ indicates that crystallization starts at about $1400^{\circ} \mathrm{C}$ in growing amorphous silica scales and, when this happens, the transport processes begin to change. This is consistent with experimental observations ${ }^{(16)}$ and is represented by the dotted line in Fig. 2. A higher activation energy suggests that oxygen diffusion in crystalline silica will occur more rapidly than in amorphous silica possibly due to mechanisma involving charged defects.

\section{2,2. Oxidation}

Upon arrival of the oxygen flux at the interior coating/substrate interface, oxidation of non-oxide compounds will occur and the formation of internal oxide products will develop, Fig. 1a. The rate at which these reactions occur will depend upon whether they are interface reaction controlled or diffusion controlled. Wang(17) provides a semi- 
quantitative treatment for the oxidation behavior of multi-phase composite materials and suggests three possible regimes: (1) No interaction between matrix and reinforcement, (2) strong interaction betwes: the maxix ghase a-d the reineorcement ghase, anc iji sometidig intermediate between 1 and 2. For those systems which form solid solution oxides, enhanced oxidation resistance for the composite is unlikely. This is because the defect structure of the less resistant oxide will be inherited by the solid solution:: In the case of amorphous silica, soluble impurities generally create diffusion space in the internal network. For those systems where the diffusion length is small compared to the average interface boundary interval, the two phases will likely oxidize independently and an additive relationship will apply to the overall kinetics. Both theoretical predictions.(17) and experimental results ${ }^{(18)}$ show that oxidation is typically, and sometimes significantly, enhanced when the fibers are oriented perpendicular to the surface, as illustrated in Fig $1 b$. This is of particular concern for sic/sic composites that utilize carbon coated fibers to reduce sliding resistance at the interface. ${ }^{(19)}$ Oxidation of the carbon coated fiber results in $c 0$ gas that rapidly diffuses to the surface and leaves an annular space between the fiber and matrix which provides a path for the continued oxidation of the fiber coating. '. In the sic/C/sic system, Iuthra(12) calculates that the depth of penetration along the interface can be nearly $1 \mathrm{~cm}$ at $900^{\circ} \mathrm{C}$ before the pathway is sealed by the formation of silica from the oxidation of the matrix and fiber phases. ... The depth of penetration actually drops with increasing temperature because the rate of oxidation is faster and sealing occurs in a shorter period of time. The apglication of a low permeability coating might have the disadvantage of extending the time required to seal the crack. Bhatt(20) reports extensive degradation in a coated sic fiber reinforced Reaction-Bonded $\mathrm{Si}_{3} \mathrm{~N}_{4}$ composite oxidized in the range of $600^{\circ} \mathrm{C}-1000^{\circ} \mathrm{C}$. However, at 
exterior surface of the composite reduced oxidation of the fiber coating and, as expected, the degree of mechanical property degradation.

Henegar and Jones ${ }^{(21)}$ showed that slow crack growth is accelerated

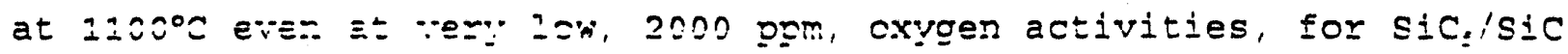
with either $C$ or $B N$ fiber coatings. For the carbon fiber coated system, crack velocities increased monotonicaily with oxygen concent up to 20,000 ppm. (22) These results suggest that time dependent properties, e.g. fatigue, creep; slow crack growth, may be harder to protect through the application of coatings.

The evolution of $\mathrm{CO}$, sio, and $\mathrm{N}$ often results from the oxidation of non-oxide compounds or by reaction between a non-oxide and its oxide scale. Examples include:

$$
\begin{gathered}
2 S i O_{2}+S i C=3 S i O(g)+C O(g) \\
2 A I N+\frac{3}{2} O_{2}=A I_{2} O_{3}+N_{2}(g)
\end{gathered}
$$

In the absence of short ci.rcuit pathways, the-e gases must diffuse back through the oxide scale and/or coating to the surface. If the rate of diffusion is too low, gas bubbles may nucleate and the pressure build to a point where the coating will crack. An example of bubble formation is shown in Fig. 3 for a silicon carbide conversion coating. The coating was formed by diffusing silicon into a carbon/carbon composite structure, as evidenced by the original fiber morphology. This particular sample was oxidized at $1650^{\circ} \mathrm{C}$ for several hours. The development of gas bubbles in the $5 \mu \mathrm{m}$ thick silica scale which formed on the surface during oxidation are in agreement with the results expected from equation 2 .

\subsection{High Temperature Corrosion}

Ceramics used in combustion environments are subject to hot corrosion if impurities such as sodium or vanadium, which exist in the 
air or in the fuel, combine with sulfur in the fuel. Corrosion occurs when molten sulfate-vanadate compounds deposit on the surface, and significant losses in strength have been observed due to pitting and

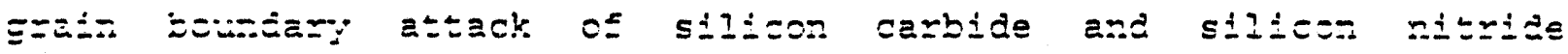
ceramics. ${ }^{(23,24)}$ Molten salt corrosion of SiC-reinforced/Si, $\mathrm{N}_{4}$ composites depends upon the type, purity, and quality of the reinforcement. Henegar and Jones(25) report significant attack in composites with Si-C-O-N type fiber reinforcements but little or no attack when the reinforcement is a high purity, single crystal, silicon carbide whisker. Slow crack growth of hot-pressed silicon nitride was also enhanced in the presence of molten $\mathrm{Na}_{2} \mathrm{SO}_{4}$ films. ${ }^{(25)}$ The penetration of sodium ions at $\mathrm{Si}_{3} \mathrm{~N}_{1}$ grain boundaries was thought to lower the melting point and viscosity of the protective silica film, increase the film deformation rate, and perhaps accelerate material transport. along grain boundaries.

High mass removal rates can also be expected for $\mathrm{Al}_{2} \mathrm{O}_{3}$, but have a strong chemical dependency favoring high suiphur and vanadium levels, 1.0 wt: and $10 \mathrm{ppm}$ respectively, but a low Na content, $1.0 \mathrm{ppm}^{(26)}$. Hwang and Rapp(27) report that vanadate ions greatly increase the acidic solubilities of all metal oxides compared to that in pure $\mathrm{Na}_{2} \mathrm{SO}_{4}$.- Even a small vanadate concentration will raise the acidic solubility of almost. any oxide. Corrosion by alkali compounds, e.g...oxides, hydroxides, and carbonates of potassium or sodium, also damage alumina silicate and silicon based ceramics.(24) Thus; coatings will be required in order to improve the corrosion resistance of ceramics and ceramics..composites. in ... highly corrosive environments:

Coatings of mullite, alumina, and yttria were shown to be effective in reducing attack on silicsn carbide heat exchanger components which survived 2000 hours, plus ten thermal cycles up to $1200^{\circ} \mathrm{C}^{(20)}$... Asilica film is expected to form underneath protective coatings applied to $\ldots . . . \cdots$ silicon base ceramic after long exposure times due to the generally low. 
resistance to the permeability of oxygen. As the silica layer thickens with time, shear forces may displace the coating or induce cracks that penetrate the coating and allow ingress of molten salt that will then

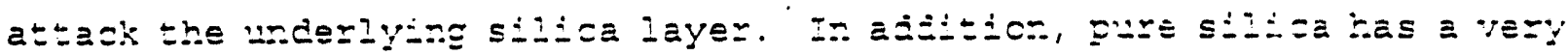
low expansion coefficient relative to other refractory oxides. This can lead to cracking and spallation if components are exposed to extensive thermal cycling.

Chlorine will also cause high temperature corrosion of ceramics(29), but the attack differs from oxidation because most chloride and oxychloride reaction products are volatile at elevated temperature. Chloride ions reduce the viscosity of silica films and the formation of bubbles can disrupt the film and accelerate the transport of oxygen.

\subsection{Mechanical stability}

The typical hierarchy in a coating selection process involves:

protection against the proposed operating environment, (2) thermochemical stability with the composite substrate, and (3) a good CTE match between coating/composite. In satisfying the first two criteria, which have been discussed in previous sections, little freedom often remains to minimize CTE differences. One very big advantage of composites is the flexibility to vary the volume fraction of the reinforcement phase to obtain a better CTE match with the coating assuming that minimum mechanical property requirements are not compromised. This is important because it is often the stress at the coating/substrate interface that exacerbates problems with adherence, Fig. 1c. The stress actually comes from two sources: (1) residual or intrinsic stress resulting from the deposition process, and (2) the difference in thermal expansion match. Some coating processes, particularly those that involve vapor deposition, condense out in a metastable or partially metastable state, and the intrinsic stresses can be quite large. It is sometimes possible to adjust the deposition 
conditions to lessen this problem, but if this fails, the coating process must be changed. A number of techniques are employed to reduce stresses induced by differential thermal expansion. The important factors are:

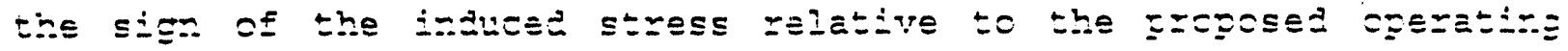
temperature, the original stress free deposition temperature, and subsequent thermal cycling conditions.

one popular approach to overcoming the CTE mismatch problem is to grade the CTE in the coating through the application of intermediate layers or by gradually mixing the composition. While this approach has been widely applied, it has not been particularly successful and generally not well understood until recently. Wiliiamson; Rabin, and Drake $^{(30)}$ modeled the thermal-residual stresses of a graded ceramic/metal interface and show reasonable validation for their approach. (31). The most significant finding was a large reduction in tshear stress in the composite below the coating interface. This result is of particular interest for weakly bonded cross ply laminates where interfacial shear failure is a concern and may occur during cool down ${ }^{(32)}$. In addition, the plastic shear strain and axial strain (e.g. normal to the coating surface) were also reduced. These results are important to the application of coatings to ductile matrix systems and to the reduction of across-ply failures. The axial or normal stresses are highest at free surfaces, and delamination of the ccating can be initiated at these points. The referenced calculations-were-for a-high modulus-(380GPA), low CTE $\left(5.4 \times 10^{-6} \%{ }^{\circ} \mathrm{K}\right)$ alumina coating on a higher expansion coefficient $\left(13.4 \times 10^{-6} /{ }^{\circ} \mathrm{K}\right)$, nickel substrate. For this . rather common coating/substrate matchup, the axial stresses actually increased in the graded conting compared with the shezp interface case. of more ... significance is the finding that the inplane stresses which promote cracking (tension) or buckling (compression) in the coating changed very little. Thus, grading is not an all encompassing answer to Crg mismatch 
problems. The functional grading of interfaces can be beneficial in certain situations such as reducing interlaminar shear when the coating has a higher modulus and is thick enough to induce subsurface stress, and in rEdu=ing acrosミ-gly strains.

It is often useful to calculate the differential thermal stress that a coating can withstand before cracking. This information is helpful for selecting the coating process and is a critical factor in the design of coatings that will be subject to thermal stresses. If edge effects are ignored, equal strain will exist in the composite and the coating at the interface. The stress in the coating can be determined, assuming isotropic conditions, by the following expression:

$$
\sigma_{c}=-\frac{\left(\alpha_{c}-\alpha_{s}\right) \Delta T}{\frac{1-\nu_{c}}{E_{c}}+\frac{1-\nu_{s}}{E_{s}} \cdot \frac{2 E_{c}}{t_{s}}}
$$

Where $\alpha_{c}$ and $\alpha_{s}$ are the thermal expansion coefficients for the coating and substrate respectively, $E_{c}$ and $E_{s}$ are the respective elastic moduli, and $v_{c}, v_{s}$ are the poissons ratios. The ratio $t_{c} / t_{s}$ represents the coating thickness divided by the half thickness of the substrate. The relationship between the differential thermal stress, $\Delta T$, needed to reach the failure stress, $T_{c}$ as a function of $t_{c} / t_{\mathrm{s}}$ are shown in Fig.4. The curves were calculated from equation 4 ; by varying the difference in coefficient of thermal expansion as well as $E_{c}$ and $E_{s}$, and setting $\nu_{c}=$ $\nu_{2}=0.2$. The coating was assumed to crack at a stress of $300 \mathrm{Mpa}$. It is seen that the ratio $t_{c} / t$; has only a small influence on the $\Delta T$ needed to induce failure below a value of 0.1 which characterizes most coating

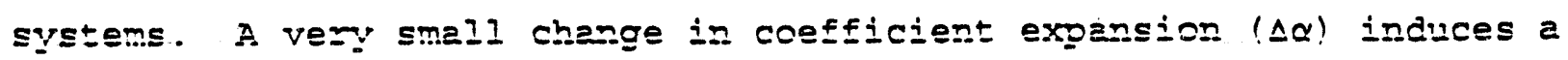
very large reduction in the temperature change, $\Delta T$, that the coating can withstand before failure. An increase in the modulus ratio $E_{c} / E_{s}$ also reduces the $\Delta T$ to failure. Thus, thicker, higher modulus, coatings could 
conceivably affect the mechanical properties of thin section composites. McCormick ${ }^{(33)}$ studied the effects of coatings on thin section carboncarbon composites and noted that some coatings significantly decreased

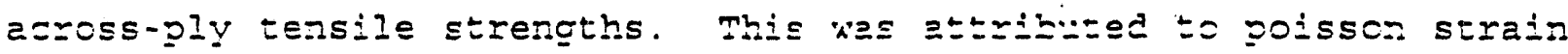
induced matrix damage and compressive stresses resulting from the CTE mismatch between coaring and the composite substrate. The damage was observed to occur during cool down after the coating was applied.

Inplane stress calculations normally assume infinitely flat interfaces which invokes a state of plane stress, e.g. there are no stresses normal to the coating surface. In reality, coatings must be applied to conners, edges, and to rough surfaces as iliustrated in-Fig. 1c. This induces normal stresses $\left(\sigma_{N}\right)$ which are proportional to the coating thickness, $t_{c}$ and-radius of curvature, $r$, as follows:

$$
\sigma_{N}=-\frac{t_{c}}{r} \sigma_{c}
$$

When the inplane stress is tensile, the normal stress is in the direction to press the coating against the substrate and can help adherence. However, when the inplane stress is compressive, the normal force is outward and, thus, becomes a detachment stress. Under these conditions, failure can occur by buckling or spalling of the coating. On the edge. face of composites where reinforcement fibers protrude to the surface, normal stresses are to be expected. - In some-instances, expensive finishing operations may be-required to polish the surface prior to coating in order to prevent spalling.

\subsection{Crack Management}

Given the complexities of managing coating stress coupled with the likelihood of processing defects, it is unreasonable to expect a perfect or crack free coating... Thus a crack management philosophy is essential 
to the long term performance of almost any coating system. A schematic of the more common conditions are shown in Fig. 1 d.

In general, thinner coatings produce a higher number of cracks per

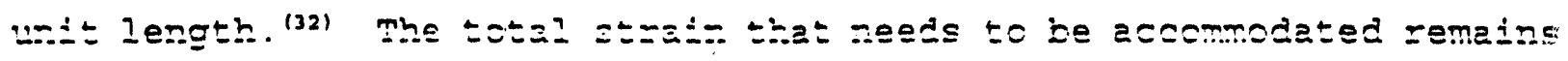
the same for either thin or thick coatings; however, a thicker coating, with fewer cracks, will have much larger crack openings. Large crack openings obviously increase the prospects of oxygen or sore other aggressive species from penetrating deeply into the composite structure and perhaps causing internal damage to fiber layers. An example of this in a coated carbon-carbon composite is shown in Fig. 5.

The relationship between crack width and ingress of molecular oxygen can be expressed through the effective diffusion coefficient, $D_{z}$ :

$$
\frac{1}{D_{E}}=\frac{1}{D_{g}}+\frac{1}{D_{x}}
$$

where $D_{g}$ is the gas phase diffusion coefficient and $D_{k}$ is the Krudsen diffusivity. The gas phase diffusivity of oxygen and air is proportional to temperature(T) and inversely proportional to the equilibrium gas pressure $\left(P_{T}\right)$ and is closely approximated by ${ }^{(34)}$ :

$$
D_{g}=9.87 \times 10^{-10} \frac{T^{3 / 2}}{P_{T}}\left(\mathrm{~m}^{2} / \mathrm{s}\right)
$$

Knudsen diffusion accounts for the collision of gas molecules along the surface of a pore or a crack. This term becomes more important as the crack width decreases. The knudsen diffusivity is normally expressed in terms of pore radius, $r$, and the molecular weight of the diffusing species, $M$, as:

$$
D_{x}=\frac{4}{3}\left(\frac{8 \cdot R}{\pi}\right) \frac{r}{2}\left(\frac{T}{M}\right)^{2 / 2} \quad\left(\pi^{2} / s\right)
$$

where $R$ is the gas constant. 
In Fig. 6, the fractional decrease in oxygen gas phase diffusion as a function of crack width is calculated using equations 6,7 , and 8 . A small correction factor(3) was applied to equation 8 to account for

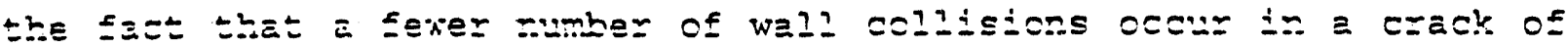
width; w, compared to a pore of radius, $r$, because of the reduced surface to volume ratio. Thus, the Knudsen diffusion coefficient, $D_{x}$, in a crack should be higher than for a pore of similar dimensions. Fig. 6 shows that crack widths will have to be $1 \mu \mathrm{m}$ or less to reduce gas phase diffusion by $25 \%$ and less than $.04 \mu \mathrm{m}$ to reduce the gas phase difussivity

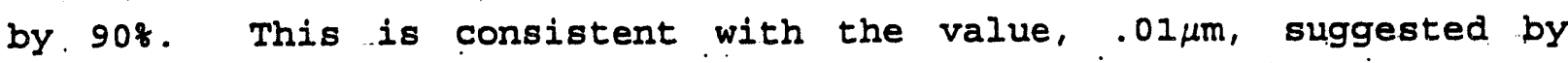
Luthra ${ }^{(35)}$.

One method to seal cracks is to employ glassy sealants. This approach has been widely used for coatings on carbon-carbon composites(36) where extensive coating cracks are unavoidable due to the extremely low expansion coefficient of the substrate. All silicon based coating systems, e.g. $\mathrm{Si}_{3} \mathrm{~N}_{4}, \mathrm{SiC}$, and $\mathrm{MOSi}_{2}$, form an amorphous silica scale that acts as a natural sealant. However, additives are employed with the silicon carbide and silicon nitride coatings used on carbon/carbon composites to help reduce glass viscosity at lower temperatures and thereby achieve wider range protection because considerable oxidation damage can occur at low temperatures for this composite. If the glass becomes too fluid at high temperatures, its oxygen permeability may be reduced significantly or it may be damaged by surface shear forces that could potentially strip away the protective layer.

Another consideration is how the glass performs when subject to thermal cycling. As the temperature drops below the glass softening point the brittle glass will fracture if the imposed stresses are in the direction to reopen cracks, but the crack surfaces will close and hopefully reseal upon the next temperature rise. However, if many repetitive cycles are incurred, the glass may eventually spall into 
pieces that can lodge in the crack, thereby preventing subsequent closure. This ratcheting process is illustrated in fig. 1e. If ratcheting occurs in a sealant system as opposed to a nonsealed system, Lhe glass phase will eventially soften and should reseal the crack; although, some internal oxidation and damage may occur before the opening can reseals itseli.

Internal sealant reservoirs are extensively utilized for coatings on carbon/carbon composites to help offset this ratcheting process and to fill flaws, defects, and cracks which provide pathways for the rapid ingress of molecular oxygen. Low melting boria glasses are used for this purpose because $\mathrm{B}_{2} \mathrm{O}_{3}$ wets carbon and silica does not. When coatings of this type are exposed to high temperatures for long periods of time, evaporation of the volatile $\mathrm{B}_{2} \mathrm{O}_{3}$ or boria doped silica becomes a problem. The calculated evaporation losses for $\mathrm{B}_{2} \mathrm{O}_{3}$ are compared with $\mathrm{SiO}_{2}$ in $\mathrm{Fig}$. 7. The curves are for an evaporation coefficient, $\alpha$, of .01, because higher evaporation coefficients are rarely measured experimentally. (37) If $\mathrm{B}_{2} \mathrm{O}_{3}$ is exposed to water vapor, the evaporation rate at $1200^{\circ} \mathrm{C}$ will increase by over three orders of magnitude. Clearly, evaporation loss is a significant concern and can be a potential performance limitation for low viscosity, volatile, sealants. Small amounts of $\mathrm{B}_{2} \mathrm{O}_{3}$ additions, e.g. 0.5-1 wt. . will also significantly increase the oxygen permeability and hence reduce the oxidation resistance of protective silica scales. (30)

\section{Summary}

A principle thesis of this review is that most composites will require protective coatings in aggressive exviromments where species such as $\mathrm{O}_{2}, \mathrm{Cl}_{2}$, or $\mathrm{S}$ exist. A number of important issues have been addressed that apply to most high-temperature coatings, and an attempt has been 
made to address problems that are specific to multi-phase composite systems.

Oxygen permeability was identified as an important criterion in the selection of protective ccatings. Composites are particularly susceptible to attack along matrix/fiber interfaces or internally within matrix cracks. Thus, aggressive species penerrate tine coating, tiney can rapidly diffuse into the interior of the composite and cause damage. The result of internal oxidation and interface degradation generally, and sometimes significantly, reduces mechanical performance. A byproduct of many interface reactions is a volatile gas. If these internally generated gases are unable to diffuse outwardly to the surface, gas bubbles will form and pressures can build to the point where damage occurs.

Ceramic composites are being considered, for expanded use in combustion system hot sections or in gas discharge regions. The presence of $\mathrm{Na}, \mathrm{s}$, or $\mathrm{V}$ impurities in the combustion products can lead to molten sulfate-vanadate condensates which are extremely corrosive. Enhanced oxide solubility in these deposits are capable of rapidly degrading coating effectiveness which may increase oxygen permeation or enable attack by other aggressive species.

While thermochemical compatibility between aggressive environments and the composite is usually the primary factor in the selection of a coating system, mechanical stability is often the determining factor in whether a coating can provide its intended function. Large differences in coefficient of thermal expansion can usually not be tolerated and may limit thermal cycle resistance. An increase in coating/substrate modulus, $E_{s} / E_{g}$, will also reduce thermal shock capability. The application of graded interfaces can be beneficial when properly designed to minimize certain types of damage such as interlaminar shear or acrossply cracking. However, grading is not generally an answer to the 
amelioration of large CTE mismatches for the prevention of inplane cracking.

Since perfect coatings are not a practical reality, some sort of crack or flaw management philosophy is an essential part of segting design. Thinner coatings produce smaller cracks which are a factor in controliing the ingress of moiecuiar species. The coating must be designed so that the cracks heal themselves at operating temperatures or sealants must be employed to fill and close openings. The application of glassy sealants which have volatile constituents, e.g. $\mathrm{B}_{2} \mathrm{O}_{3}$, must be employed with great forethought since they are subject to evaporation at high temperatures and the rates may be greatly. accelerated in the presence of moisture.

\section{References}

1. J.M. Larsen, S.M. Russ, J.W. Jones, AGARD Conference on Characterization of Fiber Reinforced Titanium Metal Matrix Composites, Sept, 1993, p.1-1.

2. J.M. Larsen, W.C. Revelos, and M.I. Gambone, Intermetallic Matrix Composite II, MRS Proceedings, Vol. 273, Materials Research Society, Pittsburg, PA, 1992, pp.3-16.

3 D.A. Woodford, D.R. Van Steele, J.A. Brehm, I.A. Timms, and J.E. Palko, J. Metals, May (1993) 57

4. E.E. Hermes, R.J. Kerans, Mat. Res. Soc. Symp. Proc., Vol. 125, 1988, P. 73 .

5. J.I. Federer, in R.E. Tressler and M. McNalion (eds.), Ceramic Transactions, Vol. 10, Amer. Cer. Soc., 1990, p. 425.

6. J.R. Price and M. van Roode, in R.E. Tressler and MCNallon (eds.), Ceramic Transactions, Vol. 10, Amer. Cer. Soc., 1990, p.469.

7. A.G. Evans, J. Am. Ceram. Soc., 73[2] (1990) 187

8. M.D. Thouless, A.G. Evans, Acta Metal1., $36[3]$ (1988) 517

9. E.I. Courtright, WL-TR-92-4009, March, 1992.

10. Y. Oishi and W.D. Kingery, J. Chem. Phys., 33, (1960) 480

11. K. Muehlenbachs and H.A. Schaeffer, Canadian Mineralogist, 15 (1977) 179-184 
12. E.I. Williams, J. Am. Ceram. Soc., 48 (1965) 190

13. T.C. Lu, A.G. Evans, R.J. Hecht, and R. Mehrabian, Acta Metall. Mater., Vol. 39, No. 8, (1991). 1853

14: F.A. Kroger, High Temperature Corrosion (R.A. Rapp, ed.), 1983 a D. $90-900$.

15. K.I. Luthra, Theoretical Aspects of the oxidation of silica-Forming Ceramics, to be Published in Proceedings of NATO Advanced Research Worksinop, to begin, Germany, (1993).

16. J.W. Fergus and W.I. Worrell, in R.E. Tressler and M. McNallon (eds.), Ceramic Transactions, Vol. 10, Amer. Cer. Soc., 1990, p. 43.

17. G. Wang "Theoretical Aspects of Oxidation of Composite Materials", presented at the 3 rd Internationsl Symposium on High Temperature Corrosios and Protection of Materials, May 1992, IES EMBIIZ, Irarce, J. Physique "in Press".

18. F.H. stott, G.C. Wood, and J.G. Fountain, Oxidation of Metals, Vol. 14, No. 1 (1980) 31

19. R.A. Lowden, Ceramic Transactions, 19 (1991) 619-630

20. R. T. Bhatt, J. Am. Ceram. Soc., 75 [2] (1992) 406-412

21. C.H. Henegar, Jr. and R.H. Jones, Ceram. Eng. Sci. Proc., 13 [7-8] (1992) 411-419

22. C.H. Henegar, Jr. and R.H. Jones, Ceram. Eng. Proceedings, 14 [7-8] 1993, to be published.

23. D.S. Fox, N.S. Jacobson, J.L. Smiakek, in R.E. Tressler and M.McNalion (eds.), Ceramic Iransaction, Vol. 10, Amer. Cer. Soc., 1990, pp. 227-249.

24. R.J. Voss, N.R. Brown, J.J. Brown, Jr., and J. Sawyer, in R.E. Tressler and M.McNallon (eds.), Ceramic Transaction, Vol. 10, Amer. Cer. Soc., 1990, pp: 411-423.

25. C.H. Henegar, Jr., and R.H. Jones, in R.E. Tressler and M.McNallon (eds.), Ceramic Transaction, Vol. 10, Amer. Cer. Soc., 1990, pp. 197-210.

26. L.Y. Cook and D.W. Bonnell, in R.E. Tressler and M.MCNallon (eds.), Ceramic Transaction, Vol. 10, Amer. Cer. Soc., 1990, pp. 251-275.

27. Y.S. Hwang and R.H. Rapp, Corrosion, 45 (11) (1989) 933-937

28. J.R. Price and M. van Roode, in R.E. Tressler and M.McNallon (eds.), Ceramic Transaction, Vol. 10, Amer. Cer. Soc., 1990, pp. 469-

29. M.J. MCNallon, S.Y. ID, S.Y. Lee, and C. Park, in R.E. Tressler and M.McNallon (eds.), ceramic Transaction, Vol. 10, Amer. Cer. Soc., 1990, pp.309-333.

30. R.I. Williamson, B.H. Rabin, and J.T. Drake, J. Appl. Phys:, 74(2) (1993) 1310 
31. J.T. Drake, R.L. Williamson, and B.H. Rabin, J. Appl. Phys., 74(2) (1993) 1321

32. W.C. Loomis and F.I. Clayton, WROC-TR-90-4109, April 1991.

33. E.S. McCormick, AFWAL-TR-86-4138, March 1987.

34. J. Szekely, J.W. Evans, and H.Y. Sohn, Gas Solid Reactions, Academic Press, New York, 1976. pp. 8-64.

35. K.I. Luchra, in R.E. Tressier and M.McNalion (eds.), Ceramic Transaction, Vol. 10, Amer. Cer. Soc., 1990, pp. 183-195.

36. J.R. Strife and J.E. Sheehan, Ceramic Bulletin, 67(2) (1988) 369

37. H.C. Graham and H.H. Davis, J. Amer. Ceram. Soc., 54 (1971) pp.8993.

38. J. Schlichting, High Temperatures-High Pressures, 14 (1982) 717-724 


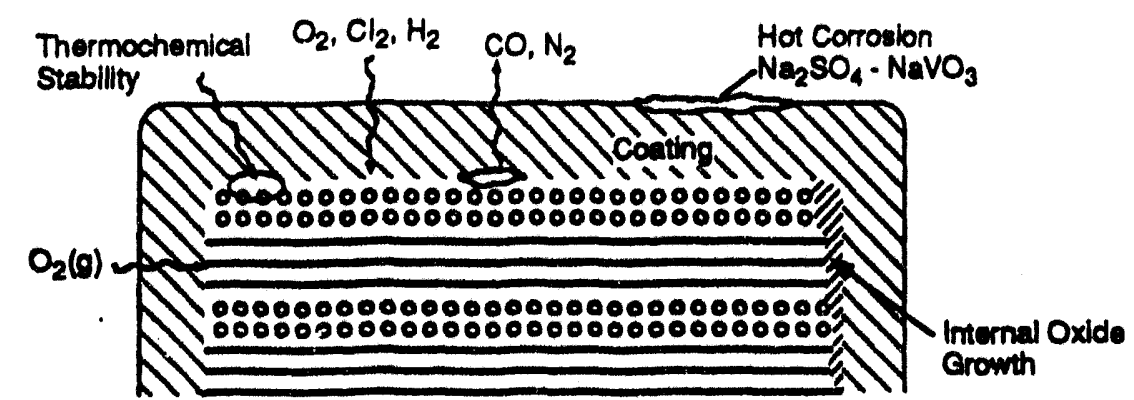

(a)



Oxygen Permeation, Hot Corrosion, Gas Evolution

\section{Internal \\ Oxidation}

Mechanical

Stability

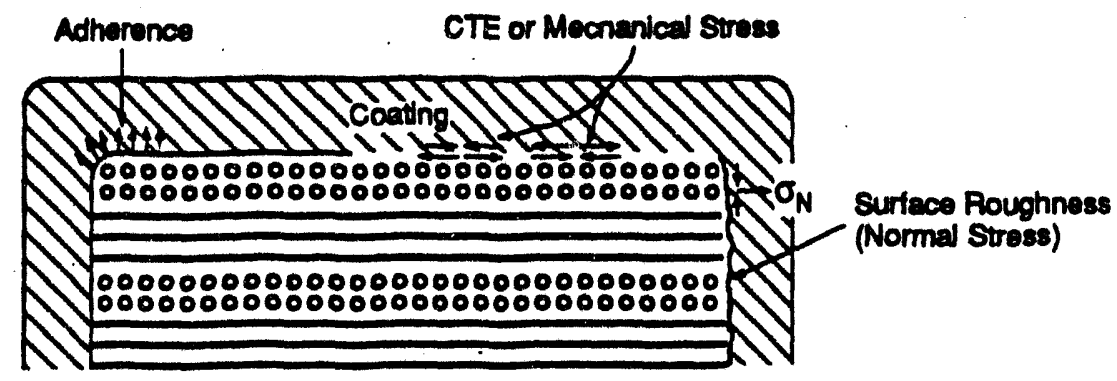

(c)

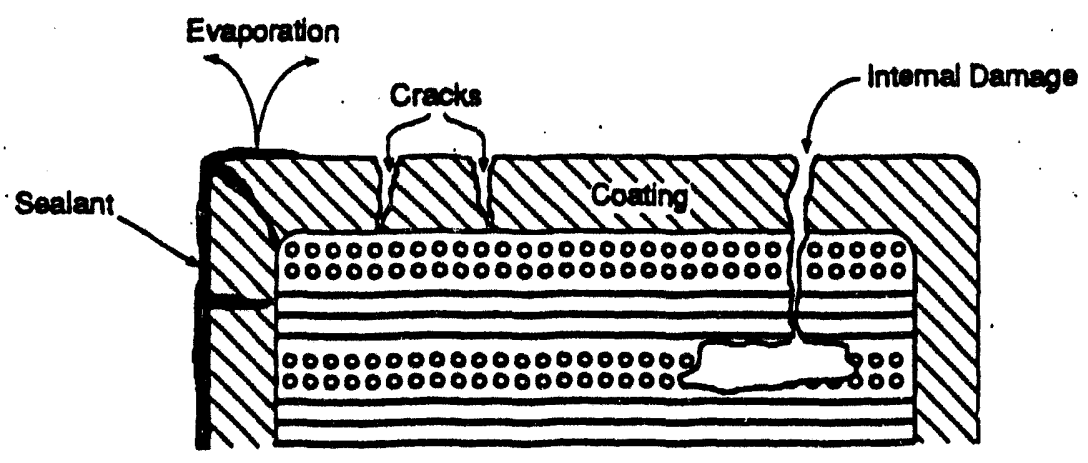

Cracks, Sealants, Internal Damage, Evaporation

(d)


Ratcheting

Fig. 1

Schematic of

typical

coating damage processes. 


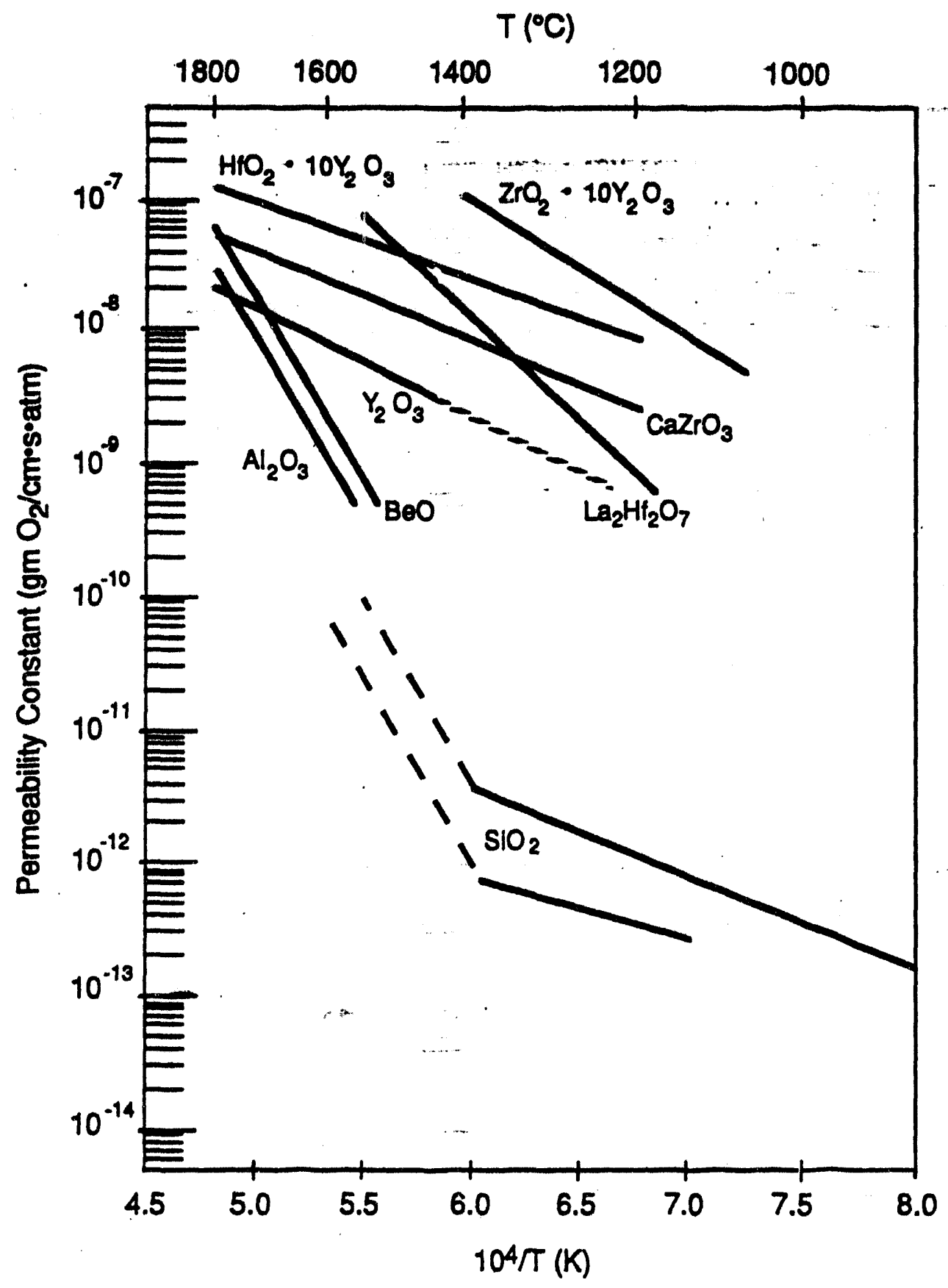

Fig. 2 Oxygen permeability in several ceramic oxides. 


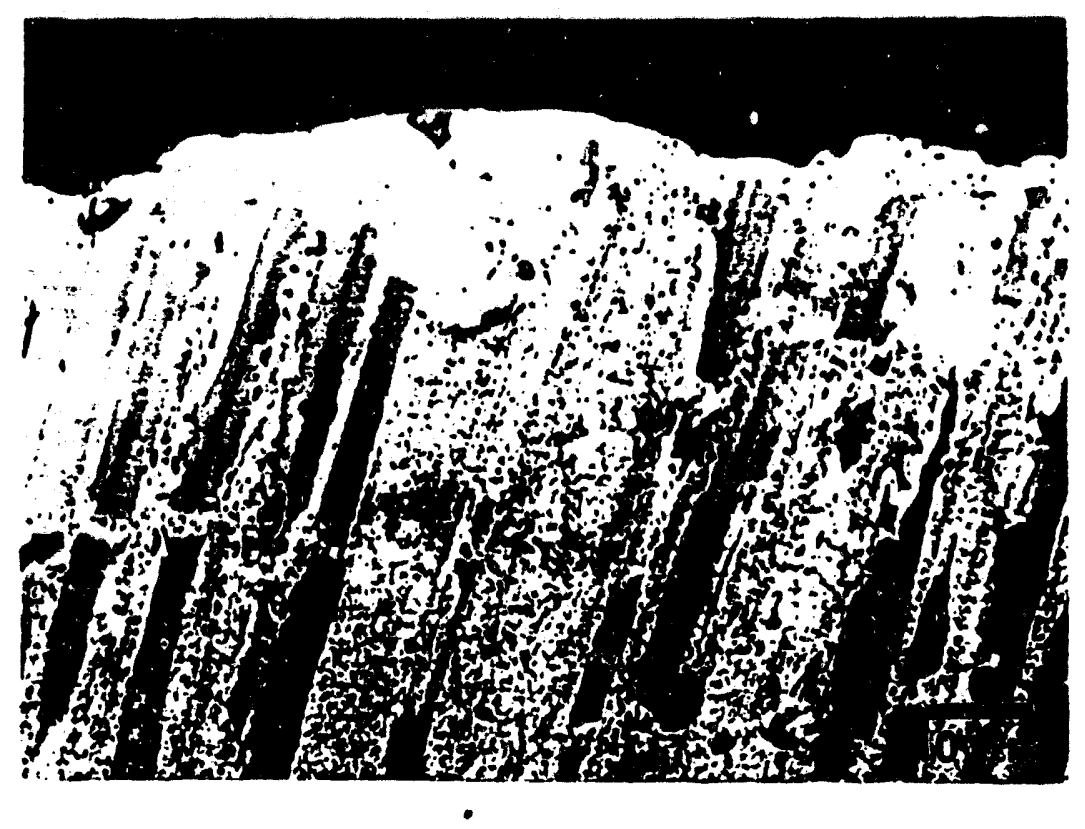

Fig. 3 Example of amorphous silica scale formation on silicon carbide after oxidation at $1650^{\circ} \mathrm{C}$ showing gas bubble formation in the silica. 


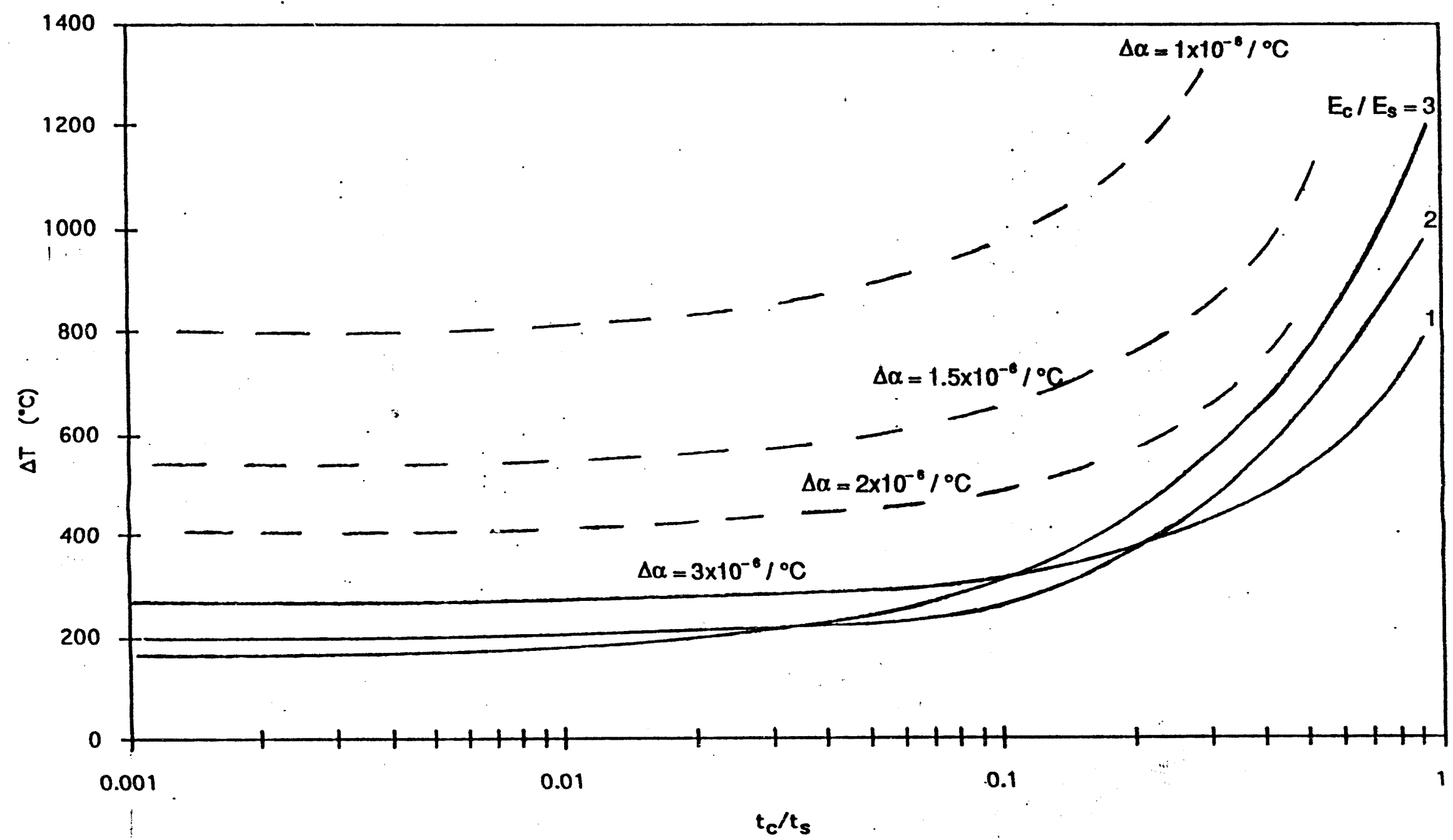

Fig. 4 Differential Temperature; $\Delta T$, needed to induce failure as a function of coating thickness/substrate thickness $\left(t_{c} / t_{g}\right)$ for a coating failure stress of 300 mpa $\left(--E_{c} / E_{a}=1\right.$; variable $\left.\Delta \alpha\right)$; $\left(-\Delta \alpha=3 \times 10^{-6} /{ }^{\circ} \mathrm{C}\right.$; variable $\left.E_{c} / E_{s}\right)$. 


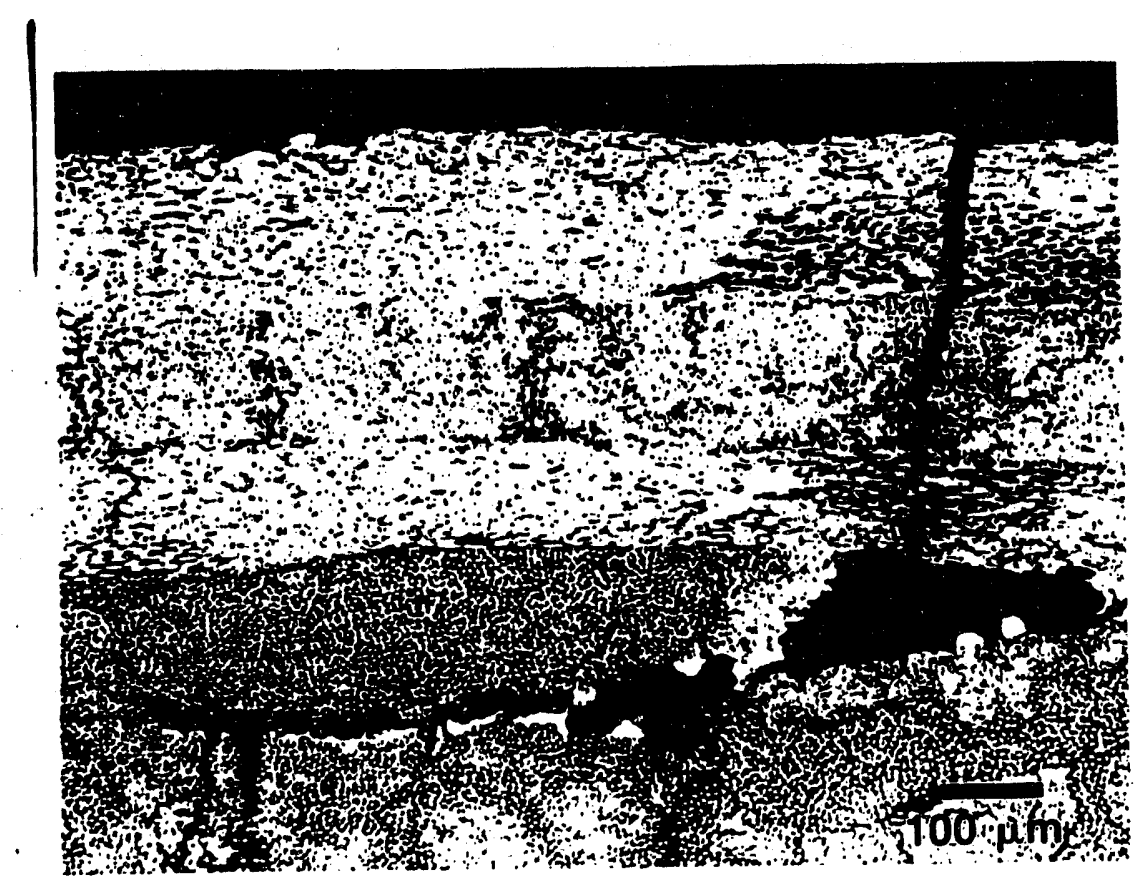

Fig. 5 Example of large crack leading to internal damage in a SiC coated carbon/carbon composite. 


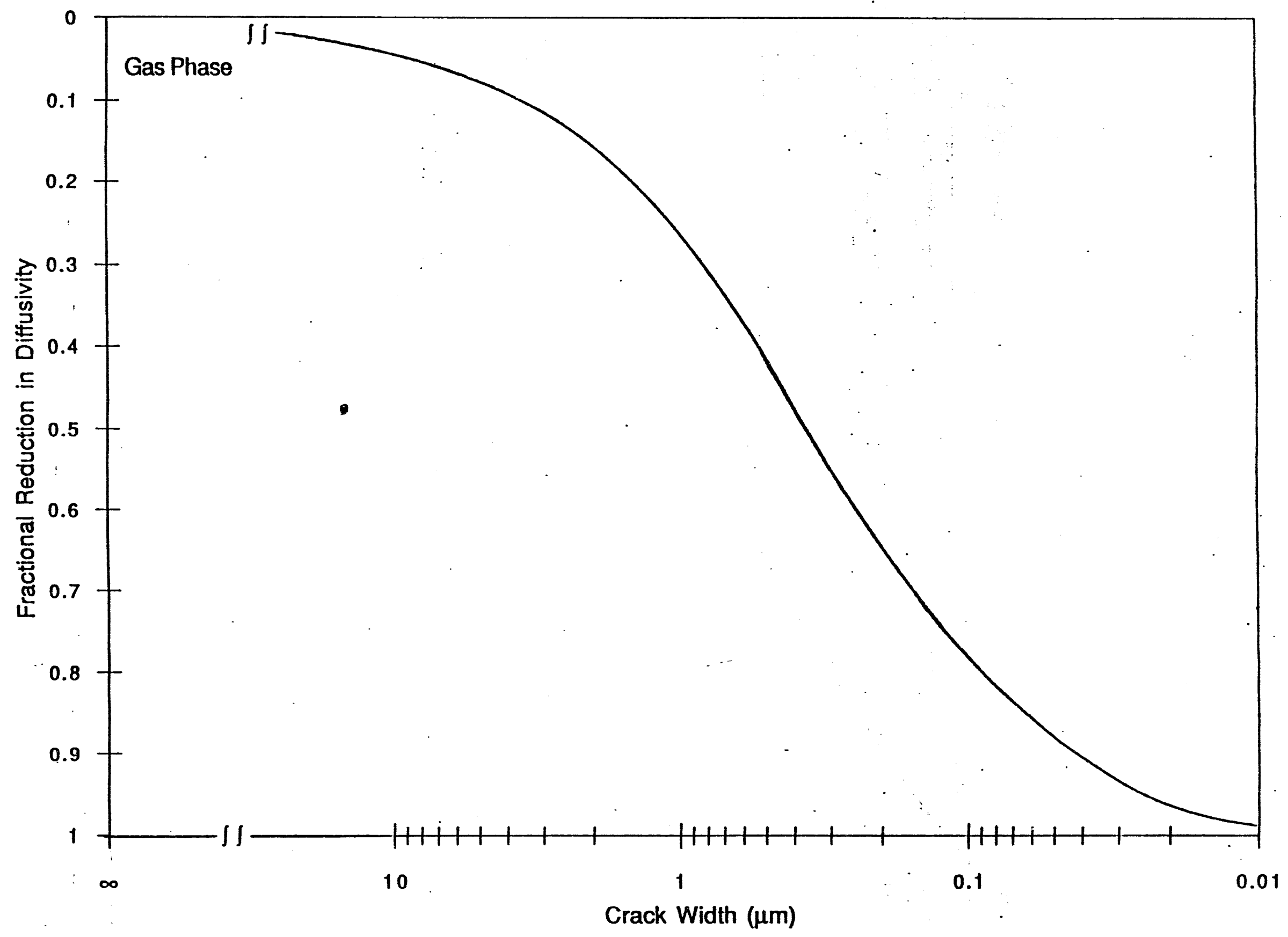

Fig. 6 Fractional decrease in oxygen diffusion as a function of crack width. 
Temperature $\left({ }^{\circ} \mathrm{C}\right)$

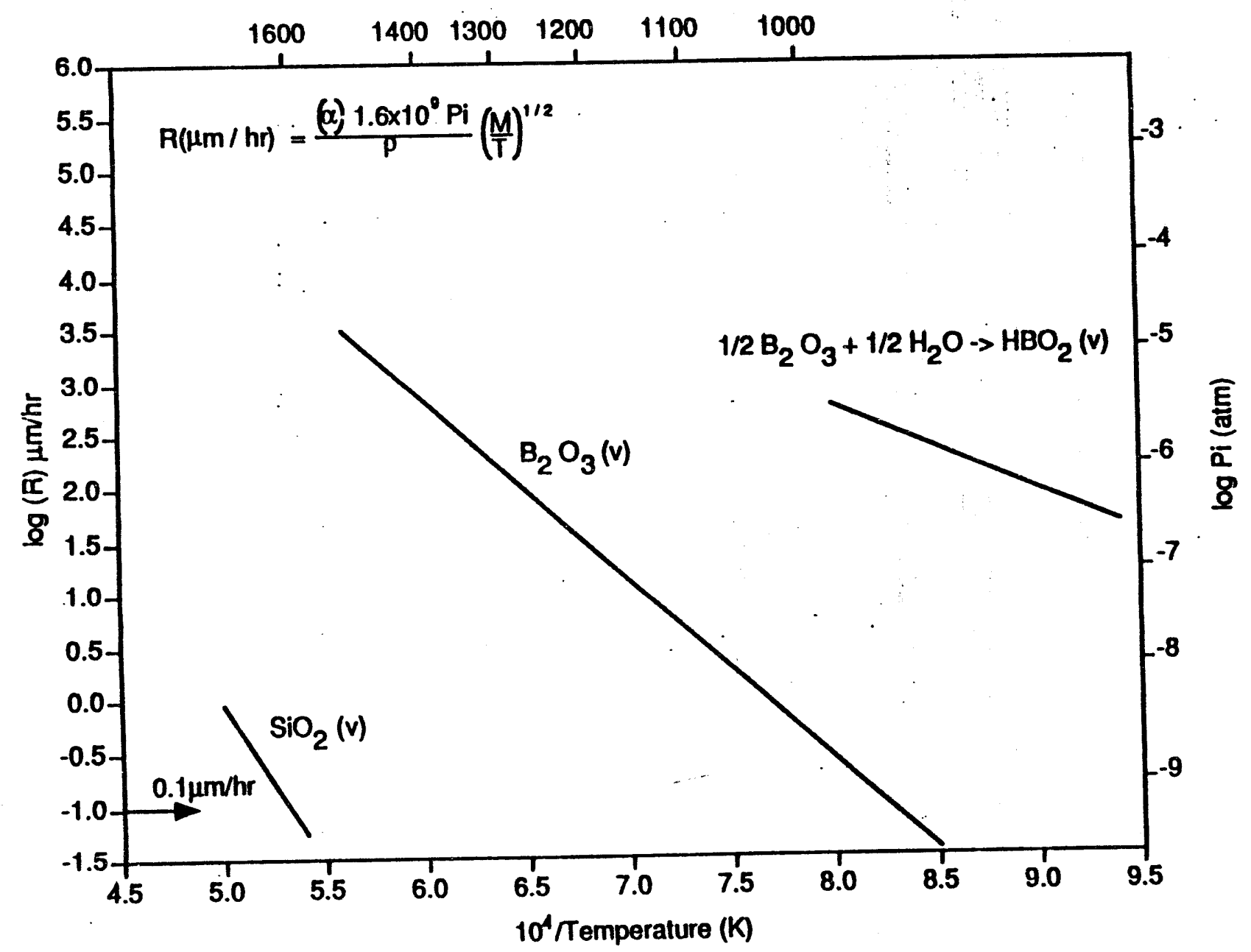

Fig. 7 Evaporation rates for $\mathrm{SiO}_{2}$ and $\mathrm{B}_{2} \mathrm{O}_{3}$. 

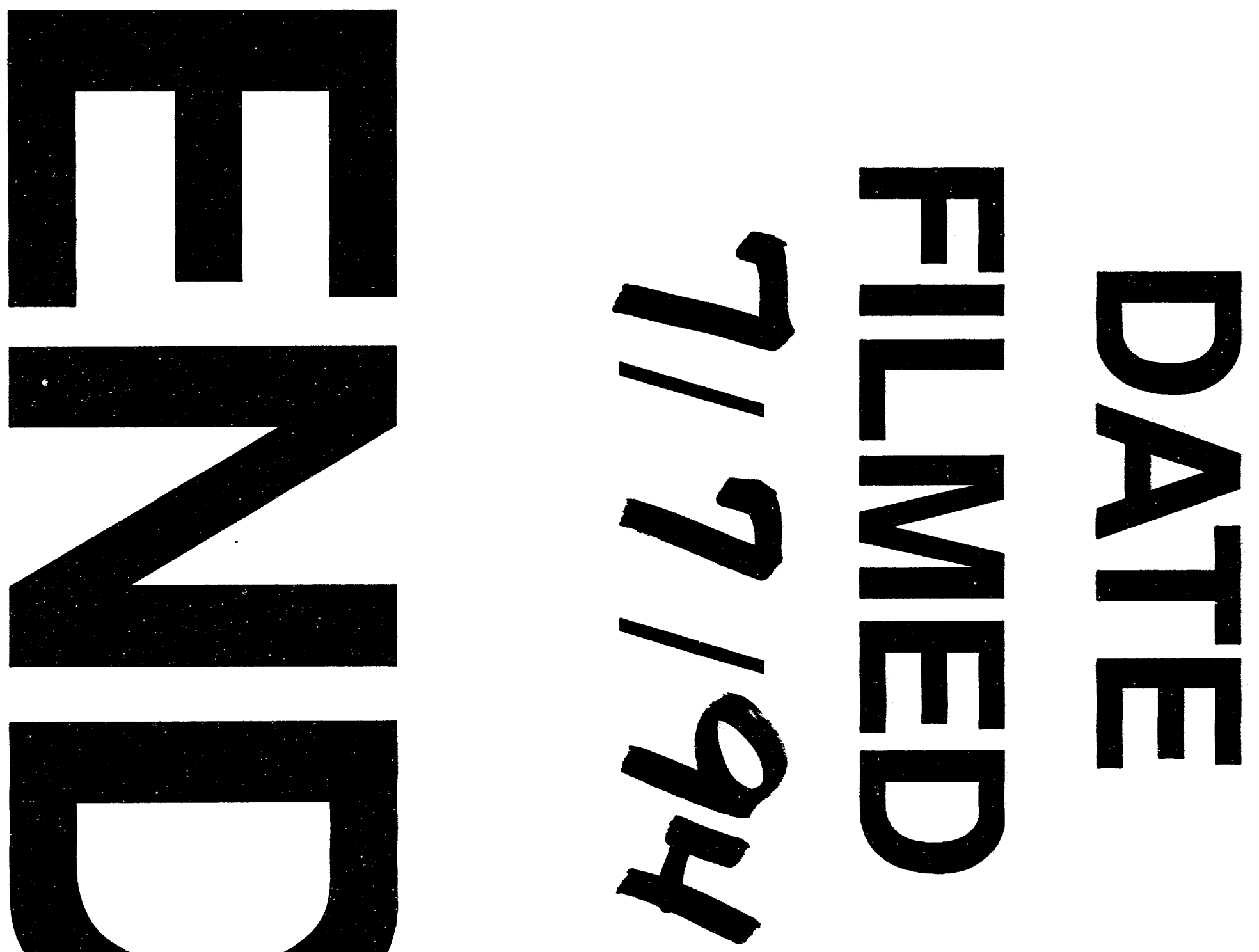

1
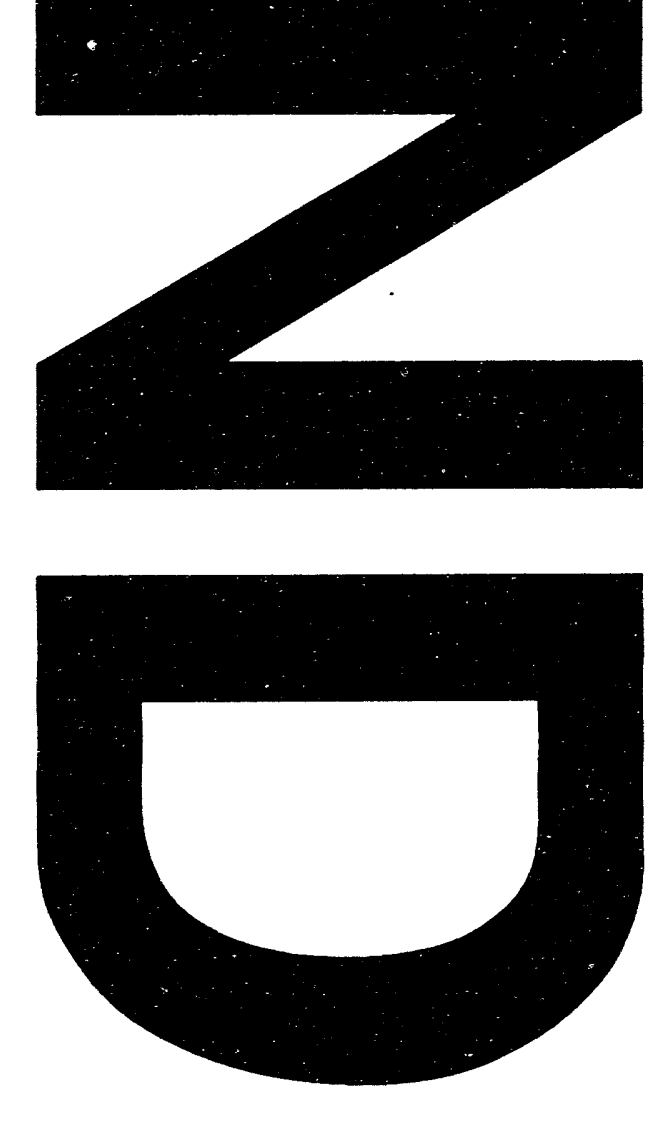

0 m 
